\title{
Relationship of the Replication and Incompatibility Genes of an IncFVI Haemolysin Plasmid with Other F-like Haemolysin Plasmids
}

\author{
By JUAN C. ZABALA, * FERNANDO de LA CRUZ AND JOSÉ M. ORTIZ \\ Departamento de Bioquímica, Facultad de Medicina, Polígono de Cazoña s/n, Santander, Spain
}

(Received 1 June 1982; revised 2 August 1982)

\begin{abstract}
The replication and incompatibility region of the IncFVI plasmid pSU 502 has been isolated by in vitro DNA manipulation as part of a $12.6 \mathrm{~kb}$ plasmid, denominated pSU503. Plasmid pSU503 was strongly incompatible with its parental plasmid, pSU1, but was fully compatible with the haemolytic plasmids pSU316 (IncFIII/IV), pHly152 (IncI2) and pSU233 (Inc-pSU233). Furthermore, the $6.9 \mathrm{~kb}$ EcoRI fragment of pSU503 which carries the replication and incompatibility determinants of pSU1 did not show any detectable homology $(<70 \%)$ with any of the haemolysin-determining plasmids with which it is compatible. Thus, homologous haemolysin determinants have become linked to apparently unrelated replicons.
\end{abstract}

\section{INTRODUCTION}

Plasmids belonging to several different incompatibility groups have been grouped together in the ' $F$ complex' because they synthesize an F-like pilus (Bradley, 1980; Willetts \& Skurray, 1980). Plasmids in the F-complex may have evolved from a common ancestral $F$ plasmid or unrelated replication and incompatibility genes may have become associated with the $F$ conjugational transfer genes by more recent illegitimate recombination events (Datta, 1979).

Plasmids determining the production of $\alpha$-haemolysin (Hly plasmids) belong to four incompatibility groups (de la Cruz et al., 1979). Among them are two sets of mutually compatible plasmids that belong to the IncF 'complex', IncFIII/IV (represented by pSU316) and IncFVI (pSU1). We have studied another Hly plasmid, pSU233, which does not determine sensitivity to the F-specific phage MS2 and is compatible with plasmids representing all known groups in the $\mathrm{F}$ complex. However, it has a core of DNA sequences of about $20 \mathrm{MDal}$ in common with all IncF plasmids and has $40 \mathrm{MDal}$ of DNA homologous to the IncFVI plasmids (de la Cruz et al., $1980 a$ ). For the purpose of this work, we shall refer to the incompatibility of this plasmid as IncpSU233. The Hly plasmids described above carry a homologous hly determinant in a $6 \mathrm{~kb}$ DNA sequence (de la Cruz et al., 1980 b).

Two alternative models can be proposed in order to explain the origin and evolution of the Flike Hly plasmids: (1) the replication and incompatibility determinants of the three Hly plasmid types could be related, but evolutionary divergence could have changed the specificity of their incompatibility determinants; (2) their replication regions could be totally unrelated. In the latter case, both the $h l y$ and the tra genes would have been added to the replicon by separate recombination events.

In order to help distinguish between these possibilities, a miniplasmid containing the basic replicon IncFVI has been constructed. It was used as a probe to detect nucleotide sequence homology between the IncFVI replication and incompatibility genes and other Hly plasmids, and to perform incompatibility tests.

\section{METHODS}

Bacterial strains and plasmids. The Escherichia coli $\mathrm{K} 12$ strains used were EC185 (prototroph, $\mathrm{F}^{-}$gyrA), DF110 (F- lac pro thi rpsL), C600 ( $\mathrm{F}^{-}$thr leu thi lac), UB5201 ( $\mathrm{F}^{-}$pro met recA56 gyrA) and UB1780 (UB5201 with Tn802 inserted in the chromosome; Bennett \& Richmond, 1976). The plasmids used are described in Table 1. 


\section{Table 1. Plasmids}

The plasmids were described by de la Cruz et al. (1979), with the exception of pHly152 (Noegel et al., 1981) and pSU503 (this work). The phenotypic abbreviations are as recommended by Novick et al. (1976). IncFIII/IV means that the plasmid is incompatible with members of both IncFIII and IncFIV incompatibility groups. Plasmid pSU233 is compatible with all the IncF plasmid prototypes (de la Cruz et $a l ., 1980 b$ ). In this work we have called it Inc-pSU233 (see text).

\begin{tabular}{|c|c|c|}
\hline Plasmid & Phenotypic markers & Derivation \\
\hline pHly152 & $\mathrm{Hly}^{+} \mathrm{IncI} 2$ & Natural isolate \\
\hline pSU316 & $\mathrm{Hly}^{+}$IncFIII/IV & Natural isolate \\
\hline pSU233 & $\mathrm{Hly}^{+}$Inc-pSU233 & Natural isolate \\
\hline pSU105 & $\mathrm{Hly}^{+}$IncFVI & Natural isolate \\
\hline pSU1 & $\mathrm{Hly}^{+}$IncFVI & Natural isolate \\
\hline pSU306 & $A p^{r}$ IncFIII/IV & pSU316hly::Tn802 \\
\hline pSU104 & $A p^{r}$ IncFVI & pSU105hly::Tn802 \\
\hline pSU502 & $A p^{r}$ IncFVI & pSU1hly::Tn802 \\
\hline pSU503 & $A p^{r}$ IncFVI & Miniplasmid derived from pSU1 \\
\hline
\end{tabular}

Genetic experiments. Procedures for bacterial growth, conjugation and incompatibility testing have been described previously (de la Cruz et al., 1979). Transformations were carried out according to Brown et al. (1979). Plasmid copy numbers were determined by the levels of ampicillin resistance $\left(\mathrm{Ap}^{\mathrm{r}}\right)$ conferred by the plasmids to otherwise isogenic strains, as described by Uhlin \& Nordstrom (1978).

Plasmid DNA isolation, restriction endonuclease digestion and electrophoresis. These techniques have been described previously (de la Cruz et al., 1979, 1980a). The plasmid screening technique used was described by Arthur \& Sherratt (1979).

Construction of the pSU503 miniplasmid. About $2 \mu \mathrm{g}$ of pSU502 DNA in a total volume of $25 \mu$ l were digested with 10 units of $E c o$ RI (Biolabs) for $1 \mathrm{~h}$ at $37^{\circ} \mathrm{C}$ in TM buffer $\left(10 \mathrm{mM}-\mathrm{MgCl}_{2}, 50 \mathrm{mM}\right.$-Tris/ $\mathrm{HCl} \mathrm{pH} \mathrm{7.5)} \mathrm{plus} 50 \mathrm{mM}$ $\mathrm{NaCl}$. At the end of the reaction period, the endonuclease was inactivated by heating $\left(10 \mathrm{~min}, 70^{\circ} \mathrm{C}\right)$. The sample was then diluted to $50 \mu \mathrm{l}$ and ATP $(0 \cdot 1 \mathrm{mM})$, DTT $(1 \mathrm{mM}), \mathrm{MgCl}_{2}(10 \mathrm{mM})$ and T4 DNA ligase (150 units : Biolabs) were added. The mixture was incubated at $14{ }^{\circ} \mathrm{C}$ for $18 \mathrm{~h}$. A $10 \mu \mathrm{l}$ sample of the ligation mixture was used to transform $200 \mu \mathrm{l}$ of competent C600 cells. The cells were diluted 10 times in Penassay broth (Difco), grown for $90 \mathrm{~min}$ and plated on Penassay agar plates containing carbenicillin $\left(500 \mu \mathrm{g} \mathrm{ml}^{-1}\right)$.

Determination of the nucleotide sequence homology of pSU503 with various Hly plasmids. Plasmid pSU503 DNA was transcribed in vitro and the ${ }^{32} \mathrm{P}$-labelled RNA transcripts hybridized to restriction fragments of the relevant plasmid DNAs in Southern blot experiments (Southern, 1975) as described previously (de la Cruz et al., $1980 \mathrm{~b}$ ). Hybridization experiments were performed under two different conditions: (1) incubation at $68^{\circ} \mathrm{C}$ in $2 \times \mathrm{SSC}$ $(1 \times \mathrm{SSC}$ is $0.15 \mathrm{M}-\mathrm{NaCl}$ plus $0.015 \mathrm{M}-\mathrm{Na}$ citrate). This allows a maximum of $15 \%$ nucleotide sequence mismatch in the heteroduplexes; (2) incubation at $51{ }^{\circ} \mathrm{C}$ in $2 \times \mathrm{SSC}$ which allows $30 \%$ nucleotide mismatch. It was assumed that the $\mathrm{G}+\mathrm{C}$ content of the plasmid DNA sequences was $50 \%$ and that a mismatching of nucleotide pairs of $1 \%$ lowers the thermal stability of the duplex by $1.4^{\circ} \mathrm{C}$ (Hyman et al., 1973).

\section{RESULTS}

\section{Construction and analysis of an IncFVI miniplasmid}

Plasmid pSU502 was derived from the IncFVI haemolytic plasmid pSU1 by insertion of the $\mathrm{Ap}^{\mathrm{r}}$ transposon Tn802 within the hly determinant (de la Cruz et al., 1979). The genetic and physical structure of the hly region of both plasmids is shown in Fig. 1. Transposon Tn802 which itself does not carry an EcoRI site was inserted in the $3.4 \mathrm{~kb} E c o$ RI fragment (termed $E c o \mathrm{~K})$ of pSU1 to produce a new fragment of $5.7 \mathrm{~kb}(E c o \mathrm{H})$ in pSU502. In addition, a deletion of $2.6 \mathrm{~kb}$ of $h l y$ plasmid DNA accompanied the insertion. Plasmid pSU502, which is $\mathrm{Ap}^{\mathrm{r}} \mathrm{Hly}^{-}$, was used in the construction of the miniplasmid because it contains a selectable phenotypic marker $\left(\mathrm{Ap}^{\mathrm{r}}\right)$ in addition to an intact IncFVI determinant (Tables 2 and 3). The miniplasmid was constructed in vitro by cleavage of pSU502 DNA with EcoRI and ligation as described in Methods. A total of $100 \mathrm{Ap}^{r}$ transformants were examined for the presence of plasmid DNA molecules by the plasmid screening technique described in Methods. A plasmid of $12.6 \mathrm{~kb}$ was detected in $70 \%$ of the strains tested. One of these was selected for further tests and the plasmid that it contained was called pSU503. The remaining transformants contained plasmids of sizes greater than $12.6 \mathrm{~kb}$ and were not analysed further. When digested with EcoRI, pSU503 DNA 


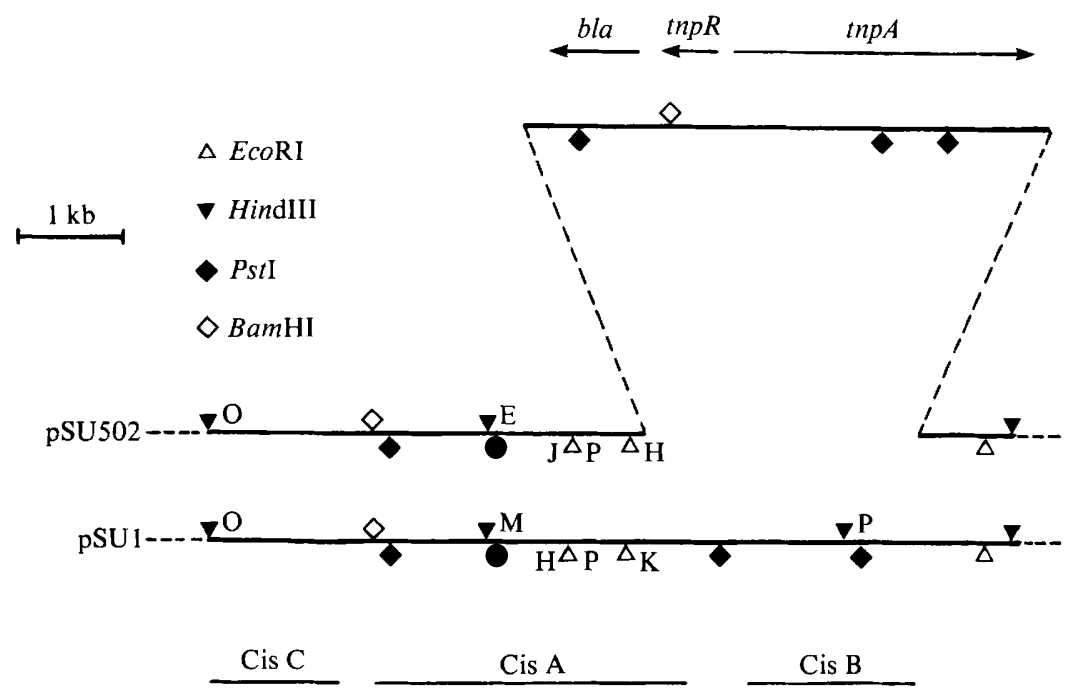

Fig. 1. Physical and functional maps of the region surrounding the haemolysin determinant of the IncFVI haemolytic plasmid pSU1 and its Tn802 insertion derivative pSU502. The capital letters above and under the lines refer to the HindIII and EcoRI restriction fragments, respectively. The physical map of the haemolysis determinant of pHly152 (Noegel et al., 1981) was found to be common to the Hiy plasmids of the IncFVI group (de la Cruz et al., 1980 b). The localization and orientation of the insertion of Tn802 in pSU1 to form pSU502 could be mapped after EcoRI, HindIII, BamHI and Pst digestion analysis (data not shown). The particular insertion studied was accompanied by a deletion of a segment of $2.5 \mathrm{~kb}$ contained within fragment EcoK of pSU1. Below the map of pSU1, the three cistrons (Cis A, B and C) comprising the hly determinant (Noegel et al., 1981) are shown. The DNA segment representing Tn802 in pSU502 is projected upwards in the pSU502 map. The localization and direction of transcription of the genes in Tn802 have been taken from Heffron et al. (1979).

Table 2. Effect of the host rec genotype on incompatibility tests with pSU503

\begin{tabular}{|c|c|c|c|}
\hline Recipient strain ${ }^{*}$ & $\begin{array}{c}\text { Relative } \\
\text { efficiency of } \\
\text { transformation } \dagger\end{array}$ & $\begin{array}{l}\text { Phenotype of } \\
\text { transformants } \ddagger\end{array}$ & Plasmids present $\S$ \\
\hline $\mathrm{F} 110(\mathrm{pSU} 1) \mathrm{rec}^{+}$ & $10^{-2}$ & $\begin{array}{l}\text { 98/100 } \mathrm{Ap}^{r} \mathrm{Hly}^{+} \\
2 / 100 \mathrm{Ap}^{r} \mathrm{Hly}^{-}\end{array}$ & $\begin{array}{l}\text { One plasmid larger than pSU1 } \\
\text { pSU } 503 \text { only }\end{array}$ \\
\hline JB5201(pSU1) recA- & $10^{-3}$ & $3 / 3 \quad \mathrm{Ap}^{r} \mathrm{Hly}^{-}$ & pSU503 only \\
\hline
\end{tabular}

* Plasmid pSU503 DNA was used to transform DF110 and UB5201 with or without pSU1. Transformants were selected on nutrient agar plates containing carbenicillin $\left(500 \mu \mathrm{g} \mathrm{ml}^{-1}\right)$.

$\dagger$ Frequency of transformation of the plasmid-containing strain divided by the frequency of transformation of the corresponding plasmid-free strain.

$\ddagger \mathrm{Ap}^{\mathrm{r}}$ colonies were replica plated using toothpicks on to blood agar plates containing carbenicillin $(500 \mu \mathrm{g}$ $\mathrm{ml}^{-1}$ ).

$\S$ DNA from cleared lysates of single colonies was analysed by agarose gel electrophoresis. The size was compared with that of pSU1 and pSU503 standards run in the same gels.

produced two fragments corresponding to fragments $E c o F(6.9 \mathrm{~kb})$ and $E c o H(5.7 \mathrm{~kb})$ of pSU502 (Fig. 2). Fragment $E c o H$ only contains DNA from the $h l y$ region of pSUl plus a copy of the transposon Tn802 (Fig. 1). Thus, the replication region of pSU502 is assumed to be contained within the $6.9 \mathrm{~kb} E c o$ RI fragment, EcoF. Plasmid pSU503 DNA was cleaved with the restriction enzymes HindIII, PstI and BamHI. These enzymes did not cleave within the $6.9 \mathrm{~kb}$ EcoRI 'replication fragment'.

The $\mathrm{Ap}^{\mathrm{r}}$ levels conferred by strains UB5201(pSU502) and UB5201(pSU503) were $1.5 \mathrm{mg} \mathrm{ml}^{-1}$. This is fivefold higher than that of strain UB1780, which contains a single copy of Tn802 inserted in the chromosome (Bennett \& Richmond, 1976). According to Uhlin \& 


\section{Table 3. Incompatibility testing of the pSU503 IncFVI miniplasmid}

Strains containing both plasmids ('doubles') were constructed by transferring the Hly plasmids to UB5201(pSU503) by conjugation and selecting for nalidixic acid resistance in blood agar plates. Single colonies were picked from the selective plates, allowed to grow in drug free nutrient broth at $37^{\circ} \mathrm{C}$ for the number of generations shown in the table and plated on nutrient agar plates as described by de la Cruz et al. (1979). For each 'double' from the matings, 100 colonies from the previous plating were replica plated, using toothpicks, on to blood agar plates containing carbenicillin. The presence of both plasmids in the colonies, except in the case of pSU105 + pSU503, was assessed by agarose gel electrophoresis of cleared lysates of eight independent colonies from each 'double'.

\begin{tabular}{cccc} 
Plasmids in the & \multicolumn{3}{c}{ Percentage of Hly Ap $^{\text {s cells }}$} \\
'doubles' & $\begin{array}{c}0 \\
\text { Generations }\end{array}$ & $\begin{array}{c}20 \\
\text { Generations }\end{array}$ & $\begin{array}{c}50 \\
\text { Generations }\end{array}$ \\
pSU105 + pSU503 & 100 & ND & ND \\
pSU233 + pSU503 & $0^{*}$ & 0 & 0 \\
pSU316 + pSU503 & 0 & 0 & 0 \\
pHly152 + pSU503 & 2 & 0 & 0
\end{tabular}

ND, Not determined.

* A total of $5 \%$ of the colonies were $\mathrm{Hly}^{-} \mathrm{Ap}^{\mathrm{r}}$. When their plasmid content was analysed, they were found to contain a single plasmid species of about $50 \mathrm{MDal}$ in size. This percentage remained constant after 50 generations of growth in the absence of selection pressure, hence the 'doubles' can be stably maintained. Presumably, the $50 \mathrm{MDal}$ plasmids arose by rec $A$-independent recombination events promoted by the IS elements present in pSU233 (Zabala et al., 1982).

Nordstrom (1978), the $\mathrm{Ap}^{\mathrm{r}}$ level is linearly related to gene copy number, so it is assumed that pSU502 and pSU503 are both present at 4-5 copies per chromosome equivalent. The low copy number of plasmid pSU503 was confirmed by comparison of the amounts of plasmid DNA present in gels as supercoiled form in relation to similar preparations of the parental plasmids (data not shown).

Strain C600(pSU503) was grown in broth in the absence of selection for plasmid maintenance for 50 generations. The culture was plated on drug-free agar medium and 100 single colonies analysed. All of them were shown to be $\mathrm{Ap}^{\mathrm{r}}$. Thus, pSU503 must contain functional genes for copy number control and partition, both of which are related to the incompatibility properties of a plasmid (Novick \& Hoppensteadt, 1978).

\section{Incompatibility tests with pSUS03}

Experiments were performed to test the incompatibility of pSU503 (Ap ${ }^{\mathrm{r}}$ ) with the plasmid from which it was derived, pSU1 $\left(\mathrm{Hly}^{+}\right)$. The results are shown in Table 2. Plasmid pSU503 was transformed into a $\mathrm{Rec}^{+}$and $\mathrm{RecA}^{-}$strain carrying pSU1. In the $\mathrm{Rec}^{+}$host $98 \%$ of the $\mathrm{Ap}^{\mathrm{r}}$ transformants were also $\mathrm{Hly}^{+}$, suggesting that the plasmids were compatible. However, in the $\mathrm{Rec}^{-}$host the $\mathrm{Ap}^{\mathrm{r}}$ transformation frequency decreased relative to the plasmid-free strain and all the $\mathrm{Ap}^{\mathrm{r}}$ transformants were $\mathrm{Hly}^{-}$. The plasmids present in these strains were examined by the screening procedure of Arthur \& Sherratt (1979). The $\mathrm{Rec}^{+}\left(\mathrm{Ap}^{\mathrm{r}} \mathrm{Hly}^{+}\right)$strain contained a single plasmid which was larger than pSU1. It was presumed that this plasmid was formed by fusion of pSU1 and pSU503 by homologous recombination. In contrast, the $\operatorname{RecA}^{-}\left(\mathrm{Ap}^{\mathrm{r}} \mathrm{Hly}^{-}\right)$strains harboured a plasmid whose mobility in agarose gels was indistinguishable from that of pSU503. Presumably pSU1 was displaced from the $\mathrm{RecA}^{-}$host by incompatibility.

The incompatibility tests described in Table 3 were performed in a $\operatorname{RecA}^{-}$host strain. The data show that pSU503 exerted strong incompatibility against pSU105 (IncFVI) but was compatible with $\mathrm{Hly}^{+}$plasmids pSU233 (Inc-pSU233), pSU316 (IncFIII/IV) and pHly152 (IncI2).

\section{Polynucleotide sequence homology between plasmid pSU503 and Hly plasmids from various incompatibility groups}

RNA labelled with ${ }^{32} \mathrm{P}$ was prepared by in vitro transcription of pSU503 DNA with $E$. coli RNA polymerase. It was used as a probe in hybridization experiments with other Hly plasmids. 

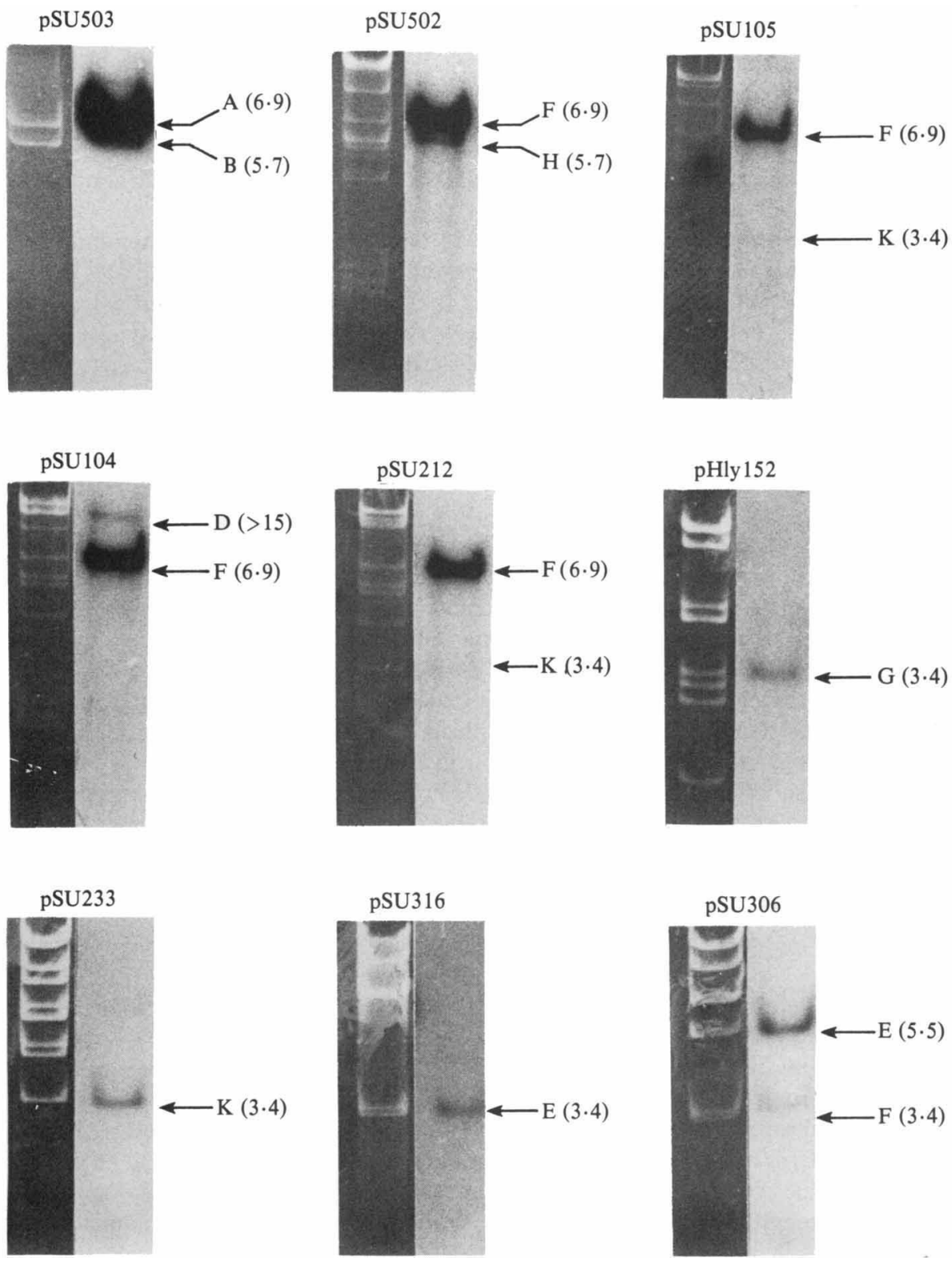

Fig. 2. Southern blot hybridization between pSU503-directed ${ }^{32} \mathrm{P}$-labelled RNA and Hly plasmid DNAs. The labelled RNA was used as a probe to hybridize with EcoRI-cleaved Hly plasmid DNAs fractionated in agarose gels as described in Methods. The results of hybridization experiments performed at $51^{\circ} \mathrm{C}$ are shown. Hybridization at $68^{\circ} \mathrm{C}$ gave the same result. The arrows beside each track indicate the EcoRI fragment(s) of the plasmid which have homology to pSU503, and the numbers in parentheses are the sizes in $\mathrm{kb}$. The inclusion of some derivatives of the Hly plasmids allowed us to distinguish between the hybridization with the different DNA segments present in pSU503 (see text). All the plasmids are described in Table 1.

The Hly plasmids, as well as derivatives with $\mathrm{Tn} 802$ insertions, were used in order to distinguish hybridization with the RNA derived from the pSU503 EcoRI fragment of $5.7 \mathrm{~kb}$ (which contained Tn 802 and part of the hly determinant; de la Cruz et al., 1980b) from hybridization to the $6.9 \mathrm{~kb}$ fragment, which is thought to carry the replication and incompatibility genes. The results of these experiments are shown in Fig. 2. 
RNA derived from the $6.9 \mathrm{~kb} E c o \mathrm{RI}$ fragment, $E c o \mathrm{~A}$, of pSU503 hybridized the same sized fragments $(E c o F)$ in the Hly IncFVI plasmids pSU105 and pSU212 and in the IncFVI carbenicillin-resistant derivatives pSU502 and pSU104. A second EcoRI fragment (EcoK) of the IncFVI Hly plasmids pSU105 and pSU212, which are known to carry part of the hly region (de la Cruz et al., 1980b), also hybridized to the RNA probe. This band was missing in the Hly : : Tn 802 insertion plasmids pSU502 and pSU104, and was replaced by larger bands $(E c o H$ in pSU502 and EcoD in pSU104).

Labelled RNA transcripts were thus obtained from both of the EcoRI fragments present in the miniplasmid pSU503. The $5.7 \mathrm{~kb}$ EcoRI fragment, $E c o \mathrm{~B}$, of pSU503 comprises $0.7 \mathrm{~kb}$ of the $h l y$ region and $5.0 \mathrm{~kb}$ of $\mathrm{Tn} 802$. It is known that the transcription of the $\operatorname{tnp} A$ gene in $\operatorname{Tn} 802$ is repressed (Gill et al., 1979) so that the hybridization that occurs with plasmids containing Tn802 will be almost entirely due to RNA molecules transcribed from the $t m p R$ and bla genes, which are about $2 \mathrm{~kb}$ in length (Heffron et al., 1979). The strength of the hybridization reaction with the IncFVI replicon fragment EcoF of pSU502, pSU105, pSU104 and pSU212 suggests that considerably more RNA is transcribed from this DNA sequence. This could reflect the greater length of DNA that could be transcribed or a more active promoter for one particular gene in this region.

The other Hly plasmids have homology with pSU503 transcripts in an EcoRI fragment of $3.4 \mathrm{~kb}$ which is known to carry part of the $h l y$ genes. The RNA molecule responsible for this hybridization is presumably derived from transcription of $h l y$ gene sequences present in pSU503. Note that $2.7 \mathrm{~kb}$ of the hly DNA contained in pSU1 fragment EcoK was lost by a deletion event that occurred at the same time as Tn 802 insertion. This $3.4 \mathrm{~kb} E c o \mathrm{RI}$ fragment was the only one to hybridize in plasmids pHly152 (IncI2), pSU233 (Inc-pSU233) and pSU316 (IncFIII/IV). This demonstrates that the replication genes of these plasmids do not have detectable homology with the IncFVI replicon in pSU503.

Finally, the plasmid pSU306, which has Tn802 inserted in fragment EcoI of pSU316, has two $E c o$ RI fragments with homology to pSU503 transcripts. This resides in fragment $E c o F$ which has $h l y$ sequences and in fragment EcoE (fragment EcoI of pSU316 plus Tn802) which carries the $\operatorname{Tn} 802$ sequences.

\section{DISCUSSION}

Plasmids that determine $\alpha$-haemolysin production have been classified in four incompatibility groups (de la Cruz et al., 1979): IncFIII/IV, represented by pSU316; IncFVI, represented by pSU1; IncI2, represented by pHly152; and pSU233 which probably represents a new group which we have provisionally called Inc-pSU233. These groups do not occur commonly among drug resistance plasmids. The Hly plasmids that belong to the $\mathrm{F}$ complex show a high degree of homology (de la Cruz et al., 1980 a). This corresponds to the tra genes (about $30 \mathrm{~kb}$ ) and the $6 \mathrm{~kb}$ $h l y$ determinant (de la Cruz et al., 1980 a, b). Furthermore, when assayed in incompatibility tests, plasmids pSU316, pSU1 and pSU233, although compatible with each other, sometimes showed a low degree of initial instability (de la Cruz et al., 1979). These results led us to postulate that the replication and incompatibility genes of these plasmids could be related to each other.

In order to verify this hypothesis, a miniplasmid containing the replication genes of the IncFVI plasmid pSU1 was constructed. This miniplasmid, called pSU503, is stably maintained at the same low copy number as its parental plasmid pSU1, and is strongly incompatible with it. However, pSU503 did not cause any detectable instability of either pSU316 or pSU233. Furthermore, the EcoRI fragment of pSU503 that contained the IncFVI incompatibility region did not show any detectable homology with pSU316, pSU233 or pHly 152 under conditions that allowed stable heteroduplex formation between polynucleotides with as much as $30 \%$ mispairing.

It is possible, however, that there are other DNA sequences located outside the $6.9 \mathrm{~kb} E c o$ RI fragment of pSU502 that are homologous to the replication regions of the plasmids analysed. In any case, this would not explain the genesis of the IncFVI replication region.

Thus, the replication and incompatibility genes of these plasmids are either completely 
unrelated or have diverged substantially in their evolution. It is possible that the dissemination of the hly determinant to otherwise unrelated replicons has occurred by means of illegitimate recombination events such as transposition or replicon fusion. It is noteworthy that we have detected several copies of the insertion sequence element IS91 in each of these Hly plasmids (Zabala et al., 1982).

We can extend this hypothesis to explain the distribution of F tra genes. In this context, we have shown that the replication genes of different Hly plasmids which have F-like tra genes are not related. Also, Palchaudhuri \& Maas (1977) compared the FI and FII incompatibility determinants by heteroduplex analysis and found that they were dissimilar. Furthermore, it has been shown (Lane, 1981) that some of the incompatibility determinants can differ considerably in their DNA sequences even within a given incompatibility group. It is conceivable that the F tra genes have become associated with different replicons by mechanisms postulated for the spread of drug resistance and other phenotypes associated with transposable elements.

This work was supported by a grant of the Comisión Asesora de Investigación Científica y Técnica. We thank Dr T. Foster for critical reading and correction of the manuscript, and Mrs Marta Garcia for her excellent assistance.

\section{REFERENCES}

ARthur, A. \& Sherratt, D. (1979). Dissection of the transposition process: a transposon encoded sitespecific recombination system. Molecular and General Genetics 175, 267-274.

Bennett, P. M. \& Richmond, M. H. (1976). Translocation of a discrete piece of DNA carrying the $a m p$ gene between replicons in Escherichia coli. Journal of Bacteriology 126, 1-6.

BradLey, D. E. (1980). Morphological and serological relationships of conjugative pili. Plasmid 4, 155-169.

Brown, M. G. M., Weston, A., Saunders, J. R. \& HUMPHREYS, G. O. (1979). Transformation of Escherichia coli $\mathrm{C} 600$ by plasmid DNA at different phases of growth. FEMS Microbiology Letters 5, 219-222.

DatTA, N. (1979). Plasmid classification: incompatibility grouping. In Plasmids of Medical, Environmental and Commercial Importance, pp. 3-12. Edited by K. N. Timmis \& A. Puhler. Amsterdam: Elsevier/ North Holland.

De la Cruz, F., Zabala, J. C. \& ORTIZ, J. M. (1979). Incompatibility among $\alpha$-hemolytic plasmids studied after inactivation of the $\alpha$-hemolysin gene by transposition of Tn802. Plasmid 2, 507-519.

DE la CruZ, F., Zabala, J. C. \& ORTIZ, J. M. (1980a). The molecular relatedness among $\alpha$-hemolytic plasmids from various incompatibility groups. Plasmid 4, 76-81.

de la Cruz, F., Müller, D., Ortiz, J. M. \& Goebel, W. $(1980 b)$. Hemolysis determinant common to Escherichia coli hemolytic plasmids of different incompatibility groups. Journal of Bacteriology 143, 825-833.

Gill, R. E., Hefreron, F. \& Falkow, S. (1979). Identification of the protein encoded by the transposable element $\operatorname{Tn} 3$ which is required for its transposition. Nature, London 282, 797-801.

HefFron, F., McCarthy, B. J., OHTSUbo, H. \& OHTSUBo, E. (1979). DNA sequence analysis of the transposon Tn $3:$ three genes and three sites involved in transposition of $\operatorname{Tn} 3$. Cell 18, 1153-1163.
Hyman, R. W., Brunovskis, I. \& Summers, W. C. (1973). DNA base sequence homology between coliphages $\mathrm{T} 7$ and $\phi \mathrm{II}$ and between $\mathrm{T} 3$ and $\phi \mathrm{II}$ as determined by heteroduplex mapping in the electron microscope. Journal of Molecular Biology 77, 189 196.

LANE, H. E. D. (1981). Replication and incompatibility of $\mathrm{F}$ and plasmids in the IncFl group. Plasmid 5, 100-126.

Noegel, A., Rdest, U. \& Goebel, W. (1981). Determination of the functions of hemolytic plasmid pHly152 of Escherichia coli. Journal of Bacteriology 145, 233-247.

Novick, R. P., Clowes, R. C., Cohen, S. N., Curtiss, R., III, DATTA, N. \& Falkow, S. (1976). Uniform nomenclature for bacterial plasmids: a proposal. Bacteriological Reviews 40, 168-189.

Novick, R. P. \& Hoppensteadt, F. C. (1978). On plasmid incompatibility. Plasmid 1, 421-434.

Palchaudhuri, S. \& MaAs, W. K. (1977). Physical mapping of a DNA sequence common to plasmids of incompatibility group F1. Proceedings of the National Academy of Sciences of the United States of America 74, 1190-1194.

SOUTHERN, E. M. (1975). Detection of specific sequences among DNA fragments separated by gel electrophoresis. Journal of Molecular Biology 98, 503-517.

Uhlin, B. E. \& Nordstrom, K. (1978). R plasmid gene dosage effects in Escherichia coli K-12: copy mutants of the R plasmid R1drd-19. Plasmid 1, 1-7.

Willets, N. \& SkurRay, R. (1980). The conjugation system of F-like plasmids. Annual Review of Genetics 14, 41-76.

Zabala, J. C., de la Cruz, F. \& Ortiz, J. M. (1982). Several copies of the same insertion sequence are present in alpha-hemolytic plasmids of various incompatibility groups. Journal of Bacteriology 151, $472-476$. 